\title{
Taking measure of mid-century modernism
}

Architectural culture still seems to be working through the consequences of the fundamental change in ideas, forms, and professional discourse that occurred somewhere between 1910 and 1970, linked inextricably to changes in how architecture became conceived in relation to wider social, cultural, and political circumstances. Shifts from what became characterised as early modernism, expressed formally through structural frames and planes, to the more diverse concerns of midcentury modern design, and then to postmodernism expressed in the visual languages of high-tech and historicism, occurred comparatively quickly - indeed potentially in the span of one architectural career. It is perhaps inevitable, then, that contemporary architects and scholars remain preoccupied with the ambitions, legacies, and unfinished projects of mid-century modernism, and continue to puzzle through what it meant then, and what it still means now. This issue of arq collects together the work of architects and scholars taking the measure of midtwentieth-century modern architecture, both as a historical phenomenon worthy of study, and as a set of ideas and practices with continuing potential.

John Tuomey trains a designer's eye on the resonant manipulation of the plan of Corbusier's Chapel of Notre Dame-du-Haut at Ronchamp (pp. 8-19). Reflecting that 'not all writing is poetry, [but] some architecture has poetic intent', he interprets the chapel in relation to poetry, examining how architects and poets shape new possibilities for meaningful form out of a limited vocabulary. The visual and cultural function of the plinth in the work of Mies van der Rohe is the focus of Tahl Kaminer's article, interpreting it as a device for isolating a building from the world around, and consequently promoting the architectural project as somehow autonomous from its environment (pp. 21-32). César Cruz, meanwhile, examines how the German-born Puerto Rican architect Henry Klumb adapted aspects of modern architecture into a more humane, environmentally- and culturally-sensitive enterprise on that island (pp. 33-46). And Daphna E. Half identifies and examines a new style emerging in Israeli architecture in the 1940s, driven by a rationalist approach and a cultural appeal to modesty, frugality and ordinariness, with particular reference to the designs of Dov Karmi (pp. 47-62). As a counterpoint to these more-or-less canonical architects and projects, Amy Clarke, Stuart King, Andrew Leach, and Wouter Van Acker highlight the sometimes anonymous but distinctive postwar fibro beach architecture of southeast Queensland, noting recent nostalgic, preservationist responses to it (pp. 63-72). Meanwhile, Guanghui Ding and Charlie Q. L. Xue root their informative account of the role of design institutes in present-day Chinese architectural production in those organisations' mid-century origins (pp. 73-86).

The papers collected here emerge from a broad sympathy towards the mid-century modern architectures at stake, accounting for their past values and present-day value. Other kinds of measure-taking in relation to this period - including those accounting for issues of gender, ethnicity, and power - have previously appeared in these pages, and will no doubt continue to do so. Our field's continuing desire to work through the consequences of mid-century modern architecture shows no sign of abating. 